\title{
Prevalence of Intra-spinal Pathologies in Adolescent Idiopathic Scoliosis Patients
}

\author{
Serdar Demiröz (ㄱ, Şevki Erdem (1) \\ ${ }^{1}$ Medicalpark Hospital, Department of Orthopaedics and Traumatology, Kocaeli, Turkey \\ ${ }^{2}$ Haydarpaşa Numune Training and Research Hospital, Clinic of Orthopaedics and Traumatology, İstanbul, Turkey
}

Cite this article as: Demiröz S, Erdem Ş. Prevalence of Intra-spinal Pathologies in Adolescent Idiopathic Scoliosis Patients. JAREM 2020;10(1): 6-9

\begin{abstract}
Objective: To evaluate the prevalence of intra-spinal pathologies (ISP) in adolescent idiopathic scoliosis patients.

Methods: We retrospectively reviewed all adolescent idiopathic scoliosis cases surgically treated in our institution between 2012 and 2015 . Patients aged less than 10 years and older than 20 years were excluded, in addition to those with no hospital records of pre-operative magnetic resonance imaging (MRI) scans or abnormal neurological examination findings. Patients who underwent revision surgery were also excluded. An experienced spinal surgeon measured curvature magnitudes in the coronal plane and thoracic kyphosis angles using the Cobb method, and a radiologist evaluated the MRI scans. The patients were then divided into an ISP group and non-ISP group and compared.

Results: After applying the exclusion criteria, 124 patients with adolescent idiopathic scoliosis were included in the study. Ten (8\%) patients had ISP. Eight patients had syringomyelia in the thoracic region, one had a Chiari malformation with syringomyelia, and one had a tethered cord. There were no statistically significant differences between the groups in terms of age, sex, magnitude of thoracic kyphosis angle, magnitude of major coronal curve or direction of the main curve in patients with AIS ( $p>0.05)$. Of the 10 patients, two with ISP, one with a tethered cord and one with a Chiari malformation required additional neurosurgical procedures prior to corrective surgery.

Conclusion: The prevalence of ISPs in AIS patients was $8 \%$. Given the risk of neurological complications, we recommend that MRI should be routinely performed in all adolescent idiopathic scoliosis patients scheduled for corrective surgery.
\end{abstract}

Keywords: Syringomyelia, adolescent idiopathic scoliosis, intra-spinal pathology, posterior instrumentation

\section{INTRODUCTION}

Scoliosis is defined as a lateral deviation of more than $10^{\circ}$ on the coronal plane. Several types of scoliosis, including congenital, neuromuscular, and idiopathic, are recognized according to etiologic factors. In the absence of any underlying etiologic factor, idiopathic scoliosis is diagnosed. Idiopathic scoliosis is subdivided into three groups according to age: infantile, juvenile or adolescent $(1,2)$. Idiopathic scoliosis is the most common type of scoliosis, and $80 \%$ of idiopathic scoliosis cases are of adolescent age (3). Posterior instrumentation and fusion with segmental pedicle screw placement are the preferred methods for surgical treatment $(3,4)$. Despite advances in technology and surgical techniques, neurological complications continue to be a major problem in corrective surgery.

According to the literature, magnetic resonance imaging (MRI) should be routinely performed for pre-operative evaluations of spinal corrective surgery for all types of scoliosis, although there is controversy about the need for MRI in AIS. MRI is considered important for several reasons, such as surgical planning, determining the surgical risk and even determining the type of scoliosis. Increased use of MRI has led to the discovery of varying rates of intra-spinal pathologies (ISPs), even in asymptomatic patients. These ISPs include syringomyelia, tethered cords, Arnold-Chiari malformations, diastematomyelia, lipomas, teratomas, dermoids and epidermoid cysts $(5,6)$. The spinal cord may be

ORCID IDs of the authors: S.D. 0000-0002-2403-3750; Ş.E. 0000-0002-3977-3380 
fusion after decortication. All the patients were mobilized the day after the surgery.

\section{Statistical Analysis}

The SPSS, version 19 (SPSS Inc., Chicago, IL) was used. Categorical data were compared using the Fisher's exact test, and continuous data were compared using the Student's t test. A p value of $<0.05$ was considered to denote statistical significance.

\section{RESULTS}

Of 154 patients, 124 were included in the study. Of these, 27 were males and 97 were females. Their mean age was 15.2 (range: 11-20) years. Ten (8\%) patients had ISPs. Eight patients had syringomyelia in the thoracic region, one had a Chiari malformation with syringomyelia, and one had a tethered cord (Table 1).

The mean magnitude of the major coronal curve was $49.9^{\circ}$, and the mean thoracic kyphosis angle was 29.2. In 110 patients, the apex of the major curve was on the right side, and it was on the left side in the other 14 patients. Sixty-three of the deformities were type 1, four were type 2, eight were type 3, one was type 4, thirty-three were type 5 , and fifteen were type 6 according to the Lenke classification.

When the two groups were compared, there were no statistically significant differences in age, sex, magnitude of thoracic kyphosis angle or magnitude of major coronal curve in patients with AIS ( $p>0.05)$. The direction of the main curve had no effect on the presence of ISPs in AIS patients ( $p>0.05$ ) (Table 2).

Two of the 10 patients with ISPs required additional neurosurgical procedures prior to corrective surgery due to the presence of a tethered cord and Chiari malformation. Detethering of the cord and decompression of the Chiari malformation were performed by neurosurgeons. Motor evoked potentials and somatosensory evoked potentials were normal throughout the corrective surgery in all the patients. There were no complications in the perioperative period, and none of the patients developed postoperative neurological deficits.

\section{DISCUSSION}

In this study, the prevalence of ISPs (syringomyelia, $n=8$; tethered cord, $n=1$; Chiari malformation, $n=1$ ) in AIS patients was $8 \%$

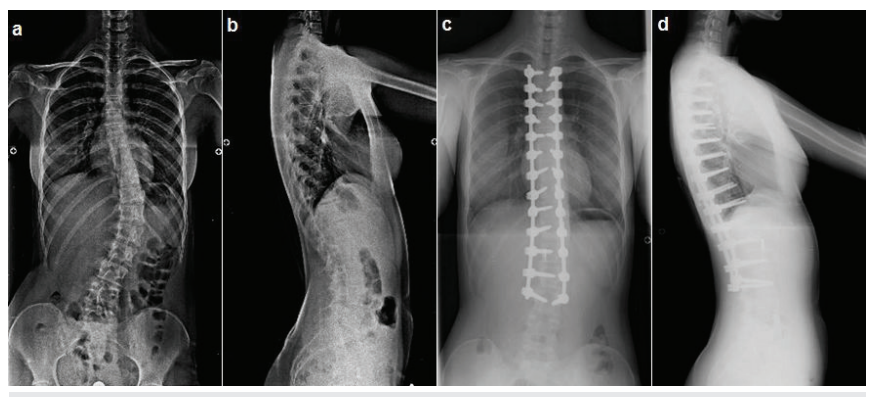

Figure 2. Preoperative and postoperative radiographs of an adolescent idiopathic scoliosis patient who underwent posterior instrumentation and fusion with segmental pedicle screws. a) preoperative anteroposterior view, b) preoperative lateral view, c) postoperative anteroposterior view, d) postoperative lateral view
Figure 1. Syringomyelia in thoracic region which may lead to a high postoperative risk of neurological complications in corrective surgery for scoliosis. a) sagittal section, b) axial section 
(10/124). Prior to corrective surgery for scoliosis, the patients with the tethered cord and Chiari malformation were operated by neurosurgeons to prevent neurological complications. No neurosurgical intervention was required in eight patients with syringomyelia only.

Previous research demonstrated that ISPs increased the risk of neurological complications after scoliosis surgery (7). Many studies have investigated the prevalence of ISPs in different types of scoliosis $(8,9)$. According to these studies, the prevalence differs markedly, depending on the type of scoliosis. The rate was lower in cases of idiopathic scoliosis, especially among adolescents, although it was higher in cases that showed rapid progression due to underlying pathologies such as congenital and neuromuscular scoliosis. Although a pre-operative evaluation by MRI is routinely recommended for all types of scoliosis, there is no consensus in the literature regarding the need for a pre-operative MRI evaluation for ISPs in AIS.

Rajasekaran et al. (10) studied 177 patients younger than 21 years. They divided the patients into three groups according to the type of scoliosis: congenital scoliosis, presumed idiopathic scoliosis, and scoliosis secondary to neurofibramatosis and neuromuscular and connective tissue disorders. They reported a prevalence of ISPs as $35 \%$ in congenital scoliosis, $16 \%$ in idiopathic scoliosis and $22 \%$ in scoliosis associated with neurofibramatosis, neuromuscular and connective tissue disorders. When they examined the subgroups of idiopathic scoliosis, the prevalence of ISPs was $14 \%$ in adolescents, $27 \%$ in juveniles and $25 \%$ in infants. In their study, young age, abnormal neurological findings and thoracic kyphosis were associated with ISPs. They recommended routine use of MRI for pre-operative evaluations in these patients.
Singhal et al. (11) retrospectively examined 206 idiopathic scoliosis patients who underwent deformity correction. Without subdividing the patient group according to age, 20 (9.7\%) of the patients had ISPs (a syrinx only, n=7; a syrinx with a Chiari type 1 malformation, $n=4$; a Chiari malformation only, $n=4$; a tethered cord, $n=2$; a split spinal cord, $n=1$; an intra-spinal tumour, $n=1$; and an arteriovenous fistula, $n=21$. All the patients with ISPs underwent an evaluation by a neurosurgeon as part of preoperative planning. Eleven of 20 patients required a neurosurgical intervention prior to corrective surgery. Given the high number of patients requiring surgical interventions (11/20), Singhal et al. (11) emphasized the need for MRI in the pre-operative evaluation of idiopathic scoliosis patients.

On the other hand, in a study by Winter et al. (12), of 140 AIS patients with ISPs (a syrinx in the thoracic region, $n=4$; a Chiari type 1 malformation, $n=3$ ) who underwent MRI before surgery, none of the patients required a neurosurgical intervention for the ISP. In this study, all the patients underwent corrective surgery without any complications. Therefore, Winter et al. (12) suggested that when the findings of a neurological examination were normal in AIS patients, there was no need for a pre-operative evaluation with MRI. Shen et al. (13) performed MRI in 72 AIS patients before corrective surgery. In their study, only two patients had ISPs, both of which were type 1 Chiari malformations. Neither of these patients required any neurosurgical intervention, and both underwent surgery for scoliosis without complications. Therefore, Shen et al. (13) advocated that there was no need for a pre-operative MRI evaluation in AIS patients before corrective surgery. On the other hand, in a study of 249 AIS patients by Ozturk et al. (14), 20 (8\%) patients had ISPs. Of these, 15 patients had syringomyelia, three

\section{Table 1. Demographics of patients with an abnormal magnetic resonance imaging}

\begin{tabular}{|c|c|c|c|c|c|c|}
\hline & Age & Sex & Pathology & Lenke & Main curve direction & Main curve magnitude \\
\hline 1 & 18 & $F$ & Syringomyelia & Type 5 & Right & 46 \\
\hline 2 & 18 & $\mathrm{~F}$ & Syringomyelia & Type 6 & Right & 44 \\
\hline 4 & 12 & $F$ & Tethered cord & Type 1 & Right & 53 \\
\hline 5 & 15 & $\mathrm{~F}$ & Syringomyelia & Type 6 & Right & 46 \\
\hline 7 & 17 & $\mathrm{~F}$ & Syringomyelia & Type 6 & Right & 50 \\
\hline 8 & 18 & $\mathrm{~F}$ & Syringomyelia & Type 1 & Right & 40 \\
\hline 9 & 12 & $\mathrm{~F}$ & Syringoöyelia & Type 1 & Right & 47 \\
\hline 10 & 14 & $\mathrm{~F}$ & Chiari type 1 & Type 1 & Right & 60 \\
\hline
\end{tabular}

\section{Table 2. Demographic comparison of patients with normal and abnormal magnetic resonance imaging findings}

\begin{tabular}{|c|c|c|c|c|c|}
\hline & Sex & Age & Direction of major curve & Major curve cobb angle & Thoracic kyphosis angle \\
\hline Non-ISP group & $\begin{array}{l}\text { M: } 26 \\
\text { F: } 88\end{array}$ & $\begin{array}{l}15.25 \pm 0.57 \\
\text { (range: } 11-20 \text { ) }\end{array}$ & $\begin{array}{l}\text { Left: } 14 \\
\text { Right: } 100\end{array}$ & $\begin{array}{l}50.16 \pm 0.96 \\
\text { (range: } 38-98 \text { ) }\end{array}$ & $\begin{array}{l}29.58 \pm 0.99 \\
\text { (range: } 12-68)\end{array}$ \\
\hline ISP group & $\begin{array}{l}\text { M: } 1 \\
F: 9\end{array}$ & $\begin{array}{l}15.40 \pm 0.17 \\
\text { (range: } 12-18 \text { ) }\end{array}$ & $\begin{array}{l}\text { Left: } 0 \\
\text { Right: } 10\end{array}$ & $\begin{array}{l}48.00 \pm 1.86 \\
\text { (range: } 40-60 \text { ) }\end{array}$ & $\begin{array}{l}25.20 \pm 2.40 \\
\text { range: } 15-42\end{array}$ \\
\hline$p$ & 0.689 & 0.616 & 0.602 & 0.516 & 0.205 \\
\hline
\end{tabular}




\section{REFERENCES}

patients had syringomyelia with a type 1 Chiari malformation, and two patients had a type 1 Chiari malformation. The three patients with syringomyelia and a type 1 Chiari malformation required neurosurgical decompression prior to corrective surgery. Therefore, in contrast to the literature, they advocated that routine MRI scanning was warranted in AIS patients, even in asymptomatic cases with no neurological complications. In the present study, the prevalence of ISPs in AIS patients scheduled for corrective surgery was $8 \%$. Two of 10 patients with ISPs (one with a type 1 Chiari malformation and one with a tethered cord) required a neurosurgical intervention before corrective surgery. Thus, we also advocate that routine MRI scanning is important for pre-operative evaluations of AIS patients.

\section{CONCLUSION}

According to the literature, all scoliosis patients should undergo a pre-operative spinal evaluation using MRI, but there is a controversy about the need for MRI in AIS patients prior to corrective surgery. In the present study, all the AIS patients were asymptomatic, with normal findings in a neurological examination. As shown by MRI, $8 \%$ of the patient population had ISPs, and two of 10 patients with ISPs required a neurosurgical intervention prior to corrective surgery. Although the prevalence of ISPs appears to be low in AIS patients, we recommend that MRI should be routinely performed in all patients scheduled for corrective surgery due to the risk of neurological complications and the widespread availability of MRI today.

Ethics Committee Approval: Retrospective study.

Informed Consent: Written informed consent, approved by our institutional review board, was obtained from all patient.

Peer-review: Externally peer-reviewed.

Author Contributions: Surgical and Medical Practices - Ş.E.; Concept S.D., Ş.E.; Design - S.D., Ş.E.; Data Collection and/or Processing - S.D.; Analysis and/or Interpretation - S.D.; Literature Search - S.D.; Writing Manuscript - S.D.

Conflict of Interest: The authors have no conflict of interest to declare.

Financial Disclosure: The authors declared that this study has received no financial support.
1. Kaufman BA. Congenital intraspinal anomalies: spinal dysraphism embryology, pathology and treatment. In: Bridwell KH, De Wald RL (eds) The textbook of spinal surgery, (2nd ed) Vol 1. Lippincott-Raven, Philadelphia, PA, 1997: 3.

2. La Grune MO, King HA. Idiopathic adolescent scoliosis: indications and expectations. In: Bridwell KH, De Wald RL (eds) The textbook of spinal surgery, (2nd ed) Vol 1. Lippincott-Raven, Philadelphia, PA, 1997: 425-50.

3. Hazebroek-Kampschreur AA, Hofman A, Van Dijk AP, Van Linge B. Prevalence of trunk abnormalities in eleven-year-old schoolchildren in Rotterdam, The Netherlands. J Pediatr Orthop 1992; 12: 480-4.

4. Ogilvie JW. Historical Aspect of scoliosis. Winter RB, Bredford DS, Lonstein JH, Ogilvie JW(eds). MOE'S Textbook of Scoliosis and Other Spinal Deformities. (3rd ed), Philadelphia: W.B. Saunders Company, 1995: 1-5.

5. Evans SC, Edgar MA, Hall-Graggs MA, Powell MP, Taylor BA, Noordeen $\mathrm{HH}$. MRI of "idiopathic" juvenile scoliosis: a prospective study. J Bone Jt Surg Br1996; 78: 314-7.

6. Ferguson RL, DeVine J, Stasikelis P, Caskey P, Allen BL Jr. Outcomes in surgical treatment of "idiopathic-like" scoliosis associated with syringomyelia. J Spinal Disord Tech 2002; 15: 301-6.

7. Noordeen MH, Taylor BA, Edgar MA. Syringomyelia: A potential risk factor in scoliosis surgery. Spine 1994; 19: 1406-9.

8. Gupta P, Lenke LG, Bridwell KH. Incidence of neural axis abnormalities in infantile and juvenile patients with spinal deformity. Is a magnetic resonance image screening necessary? Spine 1998; 23: 206-10.

9. Benli IT, Uzümcügil $O$, Aydin E, Ateş B, Gürses L, Hekimoğlu B. Magnetic resonance imaging abnormalities of neural axis in Lenke type 1 idiopathic scoliosis. Spine 2006; 31: 1828-33.

10. Rajasekaran S, Kamath V, Kiran R, Shetty AP. Intraspinal anomalies in scoliosis: An MRI analysis of 177 consecutive scoliosis patients. Indian J Orthop 2010; 44: 57-63.

11. Singhal R, Perry DC, Prasad S, Davidson NT, Bruce CE. The use of routine preoperative magnetic resonance imaging in identifying intraspinalanomalies in patients with idiopathic scoliosis: a 10-year review. Eur Spine J 2013; 22: 355-9.

12. Winter RB, Lonstein JE, Heithoff KB, Kirkham JA. Magnetic resonance imaging evaluation of the adolescent patient with idiopathic scoliosis before spinal instrumentation and fusion: a prospective, double-blinded study of 140 patients. Spine 1997; 22: 855-8.

13. Shen WJ, McDowell GS, Burke SW, Lewine DB, Chutorian AM. Routine preoperative MRI and SEP studies in adolescent patients with idiopathic scoliosis. J Pediatr Orthop 1996; 16: 350-3.

14. Ozturk C, Karadereler S, Ornek I, Enercan M, Ganiyusufoglu K, Hamzaoglu A. The role of routine magnetic resonance imaging in the preoperative evaluation of adolescent idiopathic scoliosis. Int Orthop 2010; 34: 543-6. 